\title{
MACRO-ELEMENT MODEL OF A STEEL MOMENT FRAME SUBJECTED TO FIRE-INDUCED COLUMN LOSS
}

\author{
Ha Nguyen ${ }^{\mathrm{a}}$, Ann E. Jeffers ${ }^{\mathrm{a}}$, and Venkatesh Kodur ${ }^{\mathrm{b}}$ \\ ${ }^{a}$ University of Michigan, Department of Civil and Environmental Engineering, Ann Arbor, MI, USA \\ ${ }^{\mathrm{b}}$ Michigan State University, Department of Civil and Environmental Engineering, East Lansing, MI, USA
}

\begin{abstract}
A progressive collapse mitigation strategy is to ensure load redistribution when a column fails due to fire. The study seeks to understand whether welded unreinforced flange-bolted web (WUF-B) moment connections can effectively redistribute loads in a structural system subjected to fire when a critical column is lost. A component (or macro-element) model was derived to simulate the WUF$\mathrm{B}$ connection and validated against experimental tests and high-resolution finite element (FE) models of subassemblies at room temperature and at elevated temperature. The component model was then utilized in a 2D macro FE model of a ten-story steel-framed building subjected to the loss of a column during long fire exposure. This paper presents the collapse mechanisms and quantifies structural performance based on acceptance criteria. A parametric study on location of column loss and fire occurrence is also included.
\end{abstract}

Keywords: macro-element, steel, moment frame, fire, column loss

\section{INTRODUCTION}

Progressive collapse has been accepted as a significant load case in structural design, especially for medium- and high-rise buildings. In the United States, General Service Administration (GSA) and Unified Facility Criteria (UFC) provide guidelines for progressive collapse resistant design at room temperature. Among two approaches, namely Direct Design (e.g., Alternate Path method) and Indirect Design (e.g., Tie Forces method), the majority of research on progressive collapse has focused on the Alternate Path method considering the scenario of a column removal. In this method, the structure is required to bridge the loss of a column by redistributing the load to the surrounding elements. Some examples include the Sadek et al. (2010), Khandelwal et al. (2008), and Yasser et al. (2011), which focused on structures at room temperature.

The simultaneous progressive collapse and fire hazard is rare but catastrophic. The 1995 bombing of the Alfred P. Murrah building in Oklahoma City and the collapse of WTC buildings are notable cases. Furthermore, research on structural fire has proved that significant thermal expansion followed by sudden contraction of the heated floor system during fire can produce large lateral deflections in columns, which can then lead to global collapse of the building. For example, in Lange et al. (2012) and Garlock and Quiel (2007), fire occurring or traveling to consecutive floors could result in buckling instability in perimeter columns. In another study on corner fires done by Agarwal and Varma (2014), the interior column experienced yielding and inelastic buckling failure. The NIST investigation of WTC Building 7 concluded that the global collapse of the structure was initiated by the buckling of a critical column. Therefore, in medium- and high-rise buildings, there is a need to understand structures that undergo the loss of a column during fire, which could lead to disproportionate collapse.

There have been a few studies in recent years on fire-induced progressive collapse. Some focused on collapse mechanisms in various types of structural systems while others focused on the effect of different factors on the structural behaviour. Porcari et al. (2015) summarized recent work of researchers in the field of mechanisms related to fire-induced progressive collapse, including the effect of restraint, stiffness, and bracing. Jiang et al. (2014) concluded that the common collapse modes were the lateral drift of the frames above the heated floor in association with the downward 
collapse of frames on the heated floor. Quiel and Marjanishvili (2012) studied the correlation between fire protection and the collapse time. Neal et al. (2012) investigated the effect of fire scenarios based on four parameters: fire protection, fire type, location, and fire spreading. Agarwal and Varma (2012) found that reinforcement in the floor system could play an important role in load redistribution to resist progressive collapse due to fire. Investigating the effect of bracing, Jiang et al. (2014) recommended a combination of vertical and hat bracing system in practical design.

The effect of beam-to-column connections on the global structural performance has yet been considered in current research on fire-induced progressive collapse. Most of the time, connections are simply modelled as pinned or fully rigid, which may be unreasonable given the thermal expansion and capacity degradation of those connections at elevated temperature. Furthermore, no known research has quantified the robustness of the structure in this multi-hazard scenario, leaving uncertainty in standard-based safety conclusion of those buildings. The research presented herein closes the gap by proposing a way to model framed structures using macro FE with calibrated beam-to-column connection elements and measuring the structural performance based on acceptance criteria. A parametric study on different locations of column removal and fire occurrence was also included for further understanding of failure mechanisms and identifying the most dangerous case in fire-induced progressive collapse design.

\title{
2 METHODS OF ANALYSIS
}

\subsection{Macro-element model for beam-to-column connection}

The concept of a macro-element (or component-based) model for beam-to-column connections is to use a system of springs, each of which accounts for possible failure mechanisms occurring at the connection. In the WUF-B moment connection, the failure mechanisms consist of plate bearing (shear tab and beam web), bolt shear, friction between shear tab and beam web, and compressive or tensile failure in the beam flange due to yielding or local buckling. The component model was developed based on the failure mechanisms observed in experimental tests and simulations as well as component-based models for shear connections, as introduced by Sarraj (2007). A spring represent panel zone with the stiffness presented in Khandelwal et al. (2008) was also included. Fig. 1 illustrates the component-based model for WUF-B moment connection that is proposed for elevated temperature analysis.
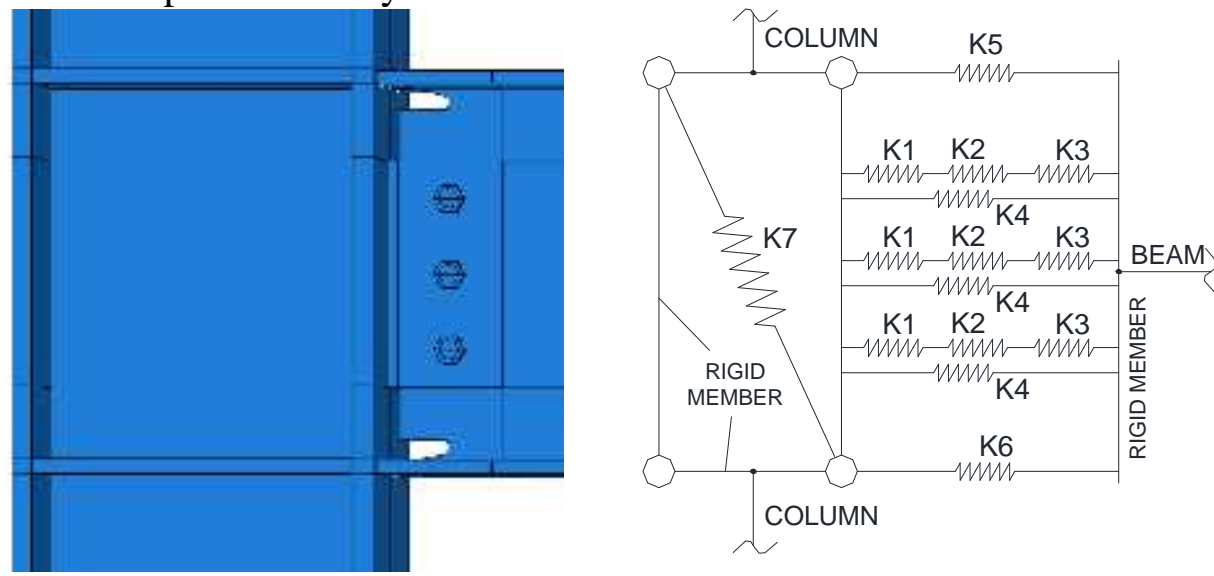

\author{
LEGEND \\ K1: SHEAR TAB IN BEARING \\ K2: BOLT IN SHEAR \\ K3: BEAM WEB IN BEARING \\ K4: FRICTION \\ K5: BEAM FLANGE IN TENSION \\ K6: BEAM FLANGE IN COMP. \\ K7: PANEL ZONE
}

Fig. 1 Macro-element model for the WUF-B connection

The force-deformation relationship of each spring was determined based on the high-resolution FE analysis of the lap joint, where one end of the shear tab was fixed and an axial load was applied evenly at the other end of the beam web, as shown in Fig. 2. Detailed explanations and formula for calculating equivalent stiffness of the spring system can be viewed in Nguyen et al. (2014). 

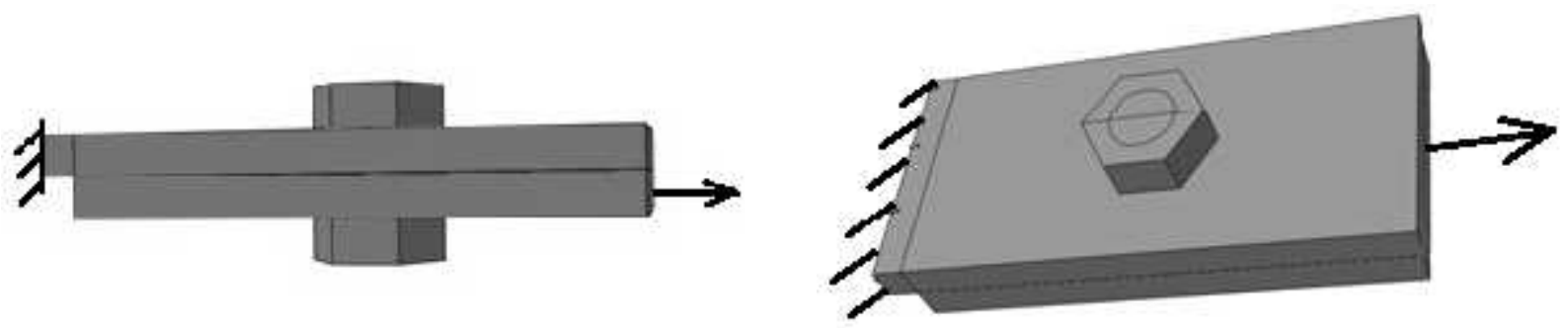

Fig. 2 Lap joint

Nguyen et al. (2014) validated the macro-element model against experimental tests and highresolution FE models of subassemblies at room temperature in Sadek et al. (2010) and at elevated temperature in Mao et al. (2009). Connections were modelled with the component elements, and the beams and columns were modelled with distributed plasticity beam elements. The close match between macro model and FE and experimental data proved the appropriateness of the connection model.

\subsection{Fire-induced progressive collapse design method}

In the presented research, the UFC (2010) Alternate Path method (i.e., column removal scenario) with nonlinear static procedure was applied to the analysis of a steel moment frame at elevated temperature. The applied loads included gravity loads and lateral loads. The increased gravity loads calculated with a dynamic factor were applied on bays immediately adjacent to and all floors above the removed column. Normal gravity loads were applied to areas away from the removed column. The lateral loads were applied to each side of the building and at the floor levels.

The fire-induced progressive collapse was simulated as fixed temperature and increasing load scenario in the macro model. The assumption is that the lateral instability of the column during long fire occurs when the entire floor reaches a constant high temperature; the load applied to the remaining structure increases as the column gradually loses its capacity and is finally removed from the system.

\subsection{Acceptance criteria for structural performance}

UFC (2010) and ASCE/SEI 41-06 (2007) provide guidelines of acceptance criteria for steel moment frames. Three performance levels were considered for building structures, namely Immediate Occupancy (IO), Life Safety (LS), and Collapse Prevention (CP). In each performance level, two criteria associated with deformation-controlled and force-controlled actions were followed. The deformation-controlled action was determined by rotation at the connections, which is typically the controlling case for beams, while the force-controlled action was determined by Demand over Capacity Ratio (DCR), which is typically the controlling case for columns. The structure was defined to fail when either action (deformation or force) reached the prescribed limit. The limiting rotation differs depending on performance level and is also dependent on the slenderness of beams or columns.

The DCR is defined as following (ASCE/SEI 41-06, 2007):

$$
\begin{gathered}
\text { For } \frac{P}{P_{C L}}<0.2, D C R=\frac{P}{2 P_{C L}}+\frac{M_{x}}{m_{x} M_{C E x}}+\frac{M_{y}}{m_{y} M_{C E y}} \leq 1.0 \\
\text { For } 0.2 \leq \frac{P}{P_{C L}} \leq 0.5, D C R=\frac{P}{P_{C L}}+\frac{8}{9}\left(\frac{M_{x}}{m_{x} M_{C E x}}+\frac{M_{y}}{m_{y} M_{C E y}}\right) \leq 1.0 \\
\text { For } \frac{P}{P_{C L}}>0.5, D C R=\frac{P}{P_{C L}}+\frac{M_{x}}{M_{C E x}}+\frac{M_{y}}{M_{C E y}} \leq 1.0
\end{gathered}
$$


where $P, M_{x}, M_{y}=$ axial force and bending moment in the member due to applied loads; $P_{C L}=$ lower bound compression strength of the member; $M_{C E x}, M_{C E y}=$ expected bending strength of the member; and $m_{x}, m_{y}=$ factor for member bending.

\section{CASE STUDY}

A ten-story steel framed building appearing in Sadek et al. (2010) was analysed in this research. The building was designed for Seismic Design Category C (SDC C) which resulted in intermediate moment frames (IMFs) as defined in the AISC (2002) seismic provisions. The 2D frame under study was the exterior moment-resisting frame, shown in Fig. 3, which used shear tab connections for bays A-C and WUF-B moment connections in bays C-F. Details for members were given in Table 1.

Table 1. Member sizes of different floor levels

\begin{tabular}{|c|c|c|c|}
\hline & Beam & Column & Shear tab \\
\hline Floor 1-3 & $\begin{array}{l}A-C: \mathrm{W} 16 \times 26 \\
C-F: \mathrm{W} 21 \times 73\end{array}$ & $\mathrm{~W} 18 \times 119$ & $1 / 2 " \mathrm{n} 12 " \mathrm{x} 6 "$ \\
\hline Floor 5-6 & $\begin{array}{l}A-C: \mathrm{W} 16 \times 26 \\
C-F: \mathrm{W} 21 \times 68\end{array}$ & $\mathrm{~W} 18 \times 97$ & $1 / 2 " \mathrm{x} 12 " \mathrm{x} 6 "$ \\
\hline Floor 8-10 & $\begin{array}{l}A-C: \mathrm{W} 16 \times 26 \\
C-F: \mathrm{W} 21 \times 44\end{array}$ & $\mathrm{~W} 18 \times 55$ & $3 / 8 " \mathrm{n} 12 " \mathrm{x} 6 "$ \\
\hline
\end{tabular}

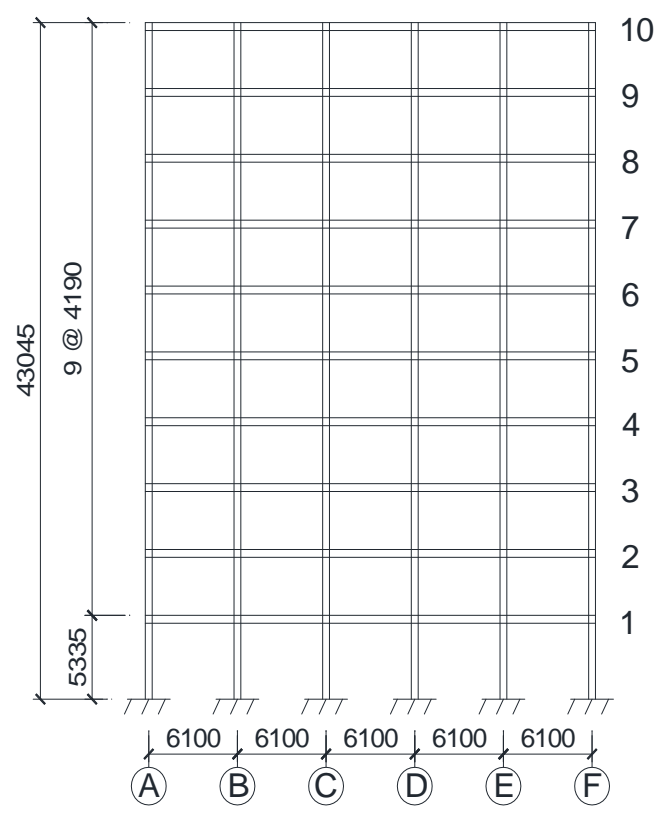

Fig. 3 Elevation view of the building

A macro-element (or component-based) model with built-in elements in ABAQUS was adopted to simulate the performance of the frame subjected to fire-induced column loss. Beams and columns were modelled as beam elements while beam-to-column connections were modelled as connector elements (Cartesian translational and rotational type). The equivalent stiffness of each connection was calculated based on the work in Nguyen et al. (2014).

Temperature was fixed and the load was increased to the design load. Temperatures of $20^{\circ} \mathrm{C}$, $400^{\circ} \mathrm{C}, 500^{\circ} \mathrm{C}, 600^{\circ} \mathrm{C}$, and the temperature that produces failure of the structure were applied to the floor of the removed column; all other floors were kept at room temperature (i.e., $20^{\circ} \mathrm{C}$ ). To further understand the collapse mechanisms and identify the most dangerous case of design, a parametric study was conducted, investigating three different locations of column loss (column D, E, and F) and three different floor levels $\left(1^{\text {st }}, 5^{\text {th }}\right.$, and $9^{\text {th }}$ floor), shown in Table 2 . In each scenario, the temperature limit and structural performance were also determined.

\section{$4 \quad$ RESULTS}

Table 2 summarizes the temperature limit, structural performance (in both deformation-controlled and force-controlled actions), and failure mechanisms in nine scenarios. 
Table 2. Temperature Limit, Structural Performance and Failure Mechanisms

\begin{tabular}{|c|c|c|c|c|c|c|}
\hline \multirow{2}{*}{ Case } & \multirow{2}{*}{$\begin{array}{c}\text { Column } \\
\text { Removed }\end{array}$} & \multirow{2}{*}{$\begin{array}{c}\text { Temperature } \\
\text { Limit }\left({ }^{\circ} \mathrm{C}\right)\end{array}$} & Structural Performance & \multicolumn{2}{|c|}{ Failure Mechanism } \\
\cline { 5 - 7 } & & DCR & Rotation & $\begin{array}{c}\text { Column failure } \\
\text { (force-controlled) })\end{array}$ & $\begin{array}{c}\text { Beam failure } \\
\text { (def.-controlled) }\end{array}$ \\
\hline 1 & Col D - Floor 1 & 610 & 1.42 & $0.037 \sim 4 \theta \mathrm{y}$ & Yes & Yes for IO \\
\hline 2 & Col E - Floor 1 & 650 & 1.09 & $0.026 \sim 3 \theta \mathrm{y}$ & Yes & Yes for IO \\
\hline 3 & Col F - Floor 1 & 590 & 1.32 & $0.070 \sim 7 \theta \mathrm{y}$ & Yes & Yes for LS \\
\hline 4 & Col D - Floor 5 & 670 & 1.22 & $0.035 \sim 3 \theta \mathrm{y}$ & Yes & Yes for IO \\
\hline 5 & Col E - Floor 5 & 690 & 1.29 & $0.040 \sim 4 \theta \mathrm{y}$ & Yes & Yes for IO \\
\hline 6 & Col F - Floor 5 & 650 & 1.15 & $0.051 \sim 5 \theta \mathrm{y}$ & Yes & Yes for IO \\
\hline 7 & Col D - Floor 9 & 640 & 0.723 & $0.084 \sim 7 \theta \mathrm{y}$ & No & Yes for LS \\
\hline 8 & Col E - Floor 9 & 630 & 0.409 & $0.056 \sim 4 \theta \mathrm{y}$ & No & Yes for IO \\
\hline 9 & Col F - Floor 9 & 610 & 0.572 & $0.071 \sim 6 \theta \mathrm{y}$ & No & Yes for LS \\
\hline
\end{tabular}

(Note for performance levels: IO - Immediate Occupancy, LS - Life Safety, CP - Collapse Prevention)

There are three major conclusions in this study.

1. Most dangerous case: The first-floor fire has the lowest temperature limit, with the loss of the corner column (i.e, column F) during a first-floor fire being the most dangerous case. The first floor columns carry the highest axial loads due to the weight of the floors above.

2. Failure modes: When fire occurs on the first and fifth floors, the dominant mode is forcecontrolled failure in column (i.e., rotations in beams are in Life Safety limit). However when fire occurs on the ninth floor, the failure mode is only deformation-controlled failure in beams (i.e., DCR of columns are in the Immediate Occupancy limit). Fig. 4 captures some major failure modes of the building in different scenarios.

3. Structural robustness: the entire building structure remains its robustness at the Life Safety level in most cases even when the temperature reaches $600^{\circ} \mathrm{C}$. It also means that the current design is sufficient to ensure life safety for the building against fire-induced progressive collapse at $600^{\circ} \mathrm{C}$.

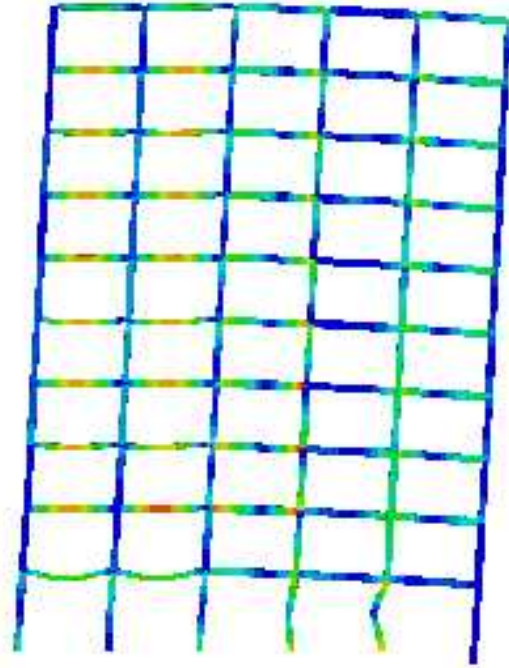

(a)

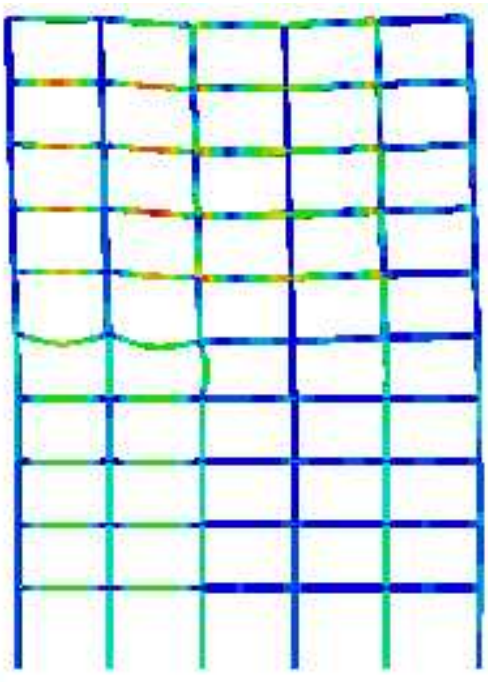

(b)

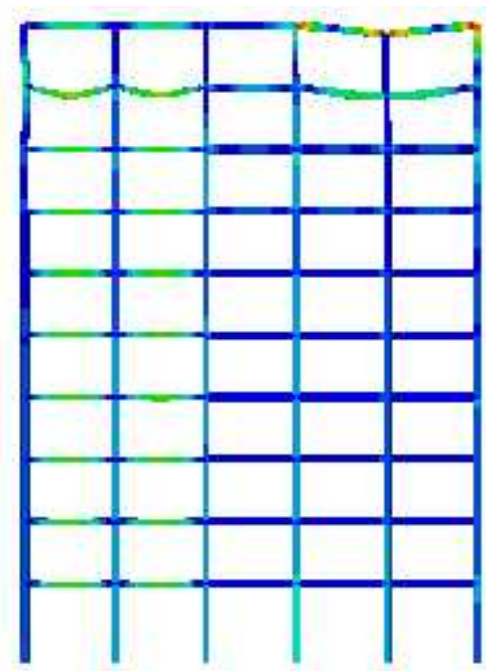

(c)

Fig. 4 Failure modes of building in (a) Scenario 3, (b) Scenario 4, (c) Scenario 8

\section{CONCLUSIONS}

A 2D macro model of a moment resisting steel frame was produced and the response of a 10-story structure was analysed under various column removal scenarios. Force-controlled and deformationcontrolled actions were assessed for various column removal scenarios at elevated temperature. It 
was found that the moment frame performed reasonably well, with capacities within the life safety limit state for temperatures up to $600^{\circ} \mathrm{C}$. An analysis of the limiting temperature for various column removal scenarios showed that a fire at the first floor was the most critical for the structure considered here and that loss of the corner column was the limiting case. Force-controlled actions dominated the failure for fires in the first and fifth floors, while deformation-controlled actions dominated the failure for fires on the ninth floor. Based on the analysis, it is believed that moment frames utilizing WUF-B connections may provide a means for mitigating fire-induced progressive collapse. Further research is needed to experimentally validate the findings of the study and to explore 3D effects.

\section{REFERENCES}

ASCE/SEI 41-06. 2007. Seismic Rehabilitation of Existing Buildings Reston, VA, USA: American Society of Civil Engineers (ASCE).

GSA. 2003. Progressive Collapse Analysis and Design Guidelines for New Federal Office Buildings and Major Modernization Projects, Washington D.C, USA: U.S. General Service Administration (GSA).

UFC 4-023-03. 2010. Design of Buildings to Resist Progressive Collapse, Washington D.C, USA: Unified Facilities Criteria (UFC) Dept. of Defense.

Agarwal A., Varma A. 2014. Fire Induced Progressive Collapse of Steel Building Structures: The Role of Interior Gravity Columns. Engineering Structures, 58, p. 129-140.

Garlock M., Quiel S. 2007. The Behavior of Steel Perimeter Columns in a High-Rise Building under Fire, Engineering Journal, 44(4), p. 359-372.

Jiang J., Li G-Q., Usmani A. 2014. Progressive Collapse Mechanisms of Steel Frames Exposed to Fire. Advances in Structural Engineering, 17(3), p. 381-398.

Jiang J., Li G-Q., Usmani A. 2014. Effect of Bracing Systems on Fire-Induced Progressive Collapse of Steel Structures Using OpenSees. Fire Technology, DOI: 10.1007/s10694-014-0451-0.

Khandelwal K., El-Tawil S., Kunnath S. K., Lew H. S. 2008. Macromodel-Based Simulation of Progressive Collapse: Steel Frame Structures. Structural Engineering, 134(7), p. 1070-1078.

Lange D., Roben C., Usmani A. 2012. Tall Building Collapse Mechanisms Initiated by Fire: Mechanisms and Design Methodology. Engineering Structures, 36, p. 90-103.

Mao C., Chiou Y., Hsiao P., Ho M. 2009. Fire Response of Steel Semi-Rigid Beam-Column Moment Connections. Constructional Steel Research, 65(6), p. 1290-1303.

Neal M.C., Garlock M., Quiel S., Marjanishvili S. 2012. Effects of Fire on a Tall Steel Building Designed to Resist Progressive Collapse, in 2012 ASCE Structures Congress, 29-31 March 2012, Chicago, Illinois, USA, p. 246-256.

Nguyen H., Jeffers A.E., Kodur V. 2014. Computational Simulation of Steel Moment Frame to Resist Progressive Collapse in Fire Scenarios, in 8th International Conference on Structures in Fire, 11-13 June 2014, Shanghai, China, p. 979-986.

Porcari G. F., Zalok E., Mekky W. 2015. Fire Induced Progressive Collapse of Steel Building Structures: A Review of the Mechanisms. Engineering Structures, 82, p261-267.

Quiel S., Marjanishvili S. 2012. Fire Resistance of a Damaged Steel Building Frame Designed to Resist Progressive Collapse. Performance of Constructed Facilities, 26(4), p. 402-409.

Sadek F., Main J., Lew H., Robert S., Chiarito V., El-Tawil S. 2010. An Experimental and Computational Study of Steel Moment Connections under a Column Removal Scenario, Gaithersburg, Maryland, USA: NIST Technical Note 1669, National Institute of Standards and Technology (NIST).

Sarraj M. 2007. The Behavior of Steel Fin Plate Connection in Fire, PhD Thesis, University of Sheffield, UK.

Yasser A., Li H., El-Tawil S. 2011. Approximations in Progressive Collapse Modelling. Structural Engineering, 137(9), p. 914-924. 